\title{
Filling machine preventive maintenance using age replacement method in PT Lucas Djaja
}

\author{
Fifi Herni Mustofa*, Ria Ferdian Utomo, and Kusmaningrum Soemadi \\ Industrial Engineering Department, Institut Teknologi Nasional, PHH. Mustafa No. 23 Bandung 40124, Indonesia
}

\begin{abstract}
PT Lucas Djaja is a company engaged in the pharmaceutical industry which produce sterile drugs and non-sterile. Filling machine has a high failure rate and expensive corrective maintenance cost. PT Lucas Djaja has a policy to perform engine maintenance by way of corrective maintenance. The study focused on the critical components, namely bearing R2, bearing 625 and bearing 626 . When the replacement of the failure done by the company is currently using the formula mean time to failure with the result of bearing R2 at point 165 days, bearing 625 at a point 205 days, and bearing 626 at a point 182 days. Solutions generated by using age replacement method with minimization of total maintenance cost given on the bearing $\mathrm{R} 2$ at a point 60 days, bearing 625 at the point of 80 days and bearing 626 at a point 40 days.
\end{abstract}

\section{Introduction}

In the drug production every pharmaceutical industry must be able to find the way in producing good medicine to guarantee and produce qualified product. Qualified products are supported by machines that can increase productivity and minimize production costs. PT Lucas Djaja is a company engaged in the pharmaceutical industry that produces sterile and non-sterile drugs. Nonsterile drugs consist of syrup, tablets, capsules and effervescent. The sterile drug consists of an ampoule injection and a vial injection. Injection drug is a sterile drug in the solution form that must be injected by tearing skin or mucous membranes.

PT Lucas Djaja has a policy to perform maintenance of the machine by means of preventive maintenance. But the maintenance process is not done regularly, so that breakdown machine can hamper production activities. Inhibition of production activities can lead to downtime, therefore by applying a good maintenance policy can improve productivity and machine performance. Machines used for the production process in manufacturing injectable drugs such as distillation machines, washing machines, mixing machines, filling machines, and autoclave machines. Among all production process machines, the machines that have an interval of failure is filling machine. PT Lucas Djaja has two injection filling machines that have the same specification but different capacity.

Filling machine is a machine that support the production process at PT Lucas Djaja, the machine has a high failure rate and expensive maintenance cost. Failure due to irregular maintenance will cause problems such as production schedules and costs incurred. At present, the company does not yet have a model to determine the schedule for preventive maintenance. Company need a maintenance schedule for prevent failure that can reduce the cost of the maintenance. Cumulative failure cost is more expensive than the cumulative preventive cost. The schedule for preventive maintenance can prevent the occurrence of failure that causes inhibition of the production process due to unplaned maintenance.

\section{Preventive Maintenance Model}

In analyzing those issues, the age replacement method is used. The age replacement method is a component replacement scheduling method based on the optimal component life [3]. This is done to minimize costs incurred by the company due to the engine failure. Preventive maintenance is done at the optimal time before the failures occurs. The determination of optimal preventive maintenance times depends on the objectives, ie minimizing costs or maximizing availability [4]. Here is a model of care policy:

1. Block Replacement, as a constant interval, because the preventive maintenance is done at definite intervals and corrective maintenance whenever required.

2. Age Replacement, the preventive maintenance time depends on the component age. If failure occurs, the component time reset to zero.

In age replacement model, the replacement policy is to perform preventive maintenance when the component reaches a certain $t_{p}$ age, as well as corrective maintenance if necessary. The purpose of this model is to determine the optimal interval of component preventive maintenance by minimizing the predicted total cost per time unit. The formula to find out the expected total maintenance cost per time unit can be seen in this equation [3];

\footnotetext{
* Corresponding author: fifi.mustofa $@$ gmail.com
} 


$$
\mathrm{C}\left(t_{p}\right) \quad=\frac{C p \times \mathrm{R}(t p)+(C f \mathrm{x}[1-R(t p)]}{(t p+T p) x R(t p)+(M(t p)+T f[1-R(t p)])}
$$

Where:

$C\left(t_{p}\right)=$ expectation of total maintenance cost per unit time $\left(t_{p}\right)$.

$C_{f}=$ the cost of corrective maintenance to preventive maintenance.

$C_{p} \quad=$ preventive maintenance cost.

$f\left(t_{p}\right)=$ probability density function .

$T_{p} \quad=$ time of preventive maintenance performance.

$T_{f} \quad=$ time moments of failure performance.

$R\left(t_{p}\right)=$ equipment and machine reliability function at $t_{p}$

$M\left(t_{p}\right)=$ meantime error of time moments of failure performance at $t_{p}$.

\section{Research Method}

The steps taken in the research method are formulate the problem, literature study, determination of resolution method, data collection and processing, analysis and conclusions.

\subsection{Formulation of the Problem}

The phase of problem identification is the first step done on this research. In the injection production there are distillation machine, washing machine, oven machine, mixer machine, filling machine and autoclave machine. PT Lucas Djaja has a policy to perform maintenance of the machine by means of preventive maintenance. But the maintenance process is not done regularly.

Based on the data of damages obtained from the company and the selection of critical machinery, filling machine is a machine that has a major impact on the production of injection. The filling machine is the most commonly damaged machine with high cost and filling machine has many machine compiler components.

No regular schedule can result in the quickly broken components, and the machine can not be operated. This can result in huge losses to the company due to the faltered of production process. Company need a maintenance schedule for prevent components failure that can reduce the cost of the maintenance.

\subsection{Literature Study}

The study of literature is the supporting theories to find resolution method. These theories are necessary in assessing the problems that occur and as a reference to solve and analyze. Theories used such as the theory of model preventive and corrective maintenance, the distribution of statistical opportunities used to test the existing failure rate [2], the distribution parameters used, the calculation of the distribution functions, the calculation of maintenance costs, and decision making for component replacement [3].

\subsection{Determination of Resolution Method}

The solution to solve the problem is to use the age replacement method. The age replacement method is a component replacement scheduling method based on the optimal component life [3]. This is done to minimize costs incurred by the company due to maintenance. The policy solution in the scheduling of preventive maintenance has a parameter that is the working day of the machine as a reference time interval for doing preventive maintenance.

\subsection{Data Collection and Analyze}

Data collections contain data of producing process of injection drugs, the failure data of each machine, critical machine, and selected machine characteristics. Component failure data consists of; maintenance time data and component failure, data of preventive maintenance cost, and component malfunction.

After the data collected and classified, it analyzes by following steps:

a. Critical Component Determination

The critical component is the component that has the biggest maintenance cost which be effected on all component maintenance cost, and it is selected using a pareto chart.

b. Calculation of Failure Interval [2]

In the data of failure component, there is information about failure date occurred; from the date can be calculated the intervals between the failure in days.

c. Calculation Pearson Product Moment Test (Index Of Fit)

The critical failure interval data is tested using 4 (four) distribution patterns, ie normal, lognormal, exponential and weibull distributions. By doing the test, it can be known that the tendency of critical component failure data follows a certain distribution pattern.

d. Calculation of Selected Failure Distribution Parameters

The failure distribution parameter is calculated based on selected distribution pattern, while the selected distribution parameters calculation aims to determine the rate of failure component and support for the calculation of the distribution function.

e. Calculation of Component Preventive Maintenance Interval [3]

In age replacement model, the replacement time interval depends on day which result the smallest value of expected total maintenance cost.

\subsection{Analysis and Conclusions}

After the data processing phase it will be done analysis of the data processing results. Includes failure data analysis, selected distribution patterns, time interval analysis between failure and cost comparison analysis of preventive replacement intervals optimally under current conditions. 
The conclusion contains results from research at PT Lucas Djaja. Based on these conclusions, the suggestion is in the form of improvement.

\section{Numerical Problem}

\subsection{Data Collecting}

Data collections contain data of the failure data of each machine, critical machine, selected machine characteristics, and component critical machine are failure data that consists; maintenance time and failure of the components and the cost of preventive maintenance and corrective maintenance.

\subsubsection{Critical Machine and Component Selection}

The critical machine selected is the filling machine based on the highest failure frequency. Selection of the critical machine uses Pareto chart.

The filling machine failures is the result of components failure. Good component conditions can have a good effect on the machine. But if the component condition is badly it will result in defective product or the machine will not be used for production process. Filling machine has five of components that often suffered damage are bearing $\mathrm{R} 2$, bearing 625 , bearing 626 , bearing 607 and roller.

\subsubsection{Preventive Maintenance and Corrective Maintenance Duration}

Preventive and corrective maintenance activities are the failure component replacement, including time open cover and shut down the machine. The duration time is based on interviews with the maintenance technicians who directly handle the machine breakdown. Duration of preventive and corrective maintenance component of filling machine can be seen on Table 1 .

Table 1. Duration Preventive and Corrective Maintenance

\begin{tabular}{|l|c|c|}
\hline Component & $\begin{array}{c}\text { Preventive } \\
\text { maintenance } \\
\text { duration (hour) }\end{array}$ & $\begin{array}{c}\text { Corrective } \\
\text { maintenance } \\
\text { duration (hour) }\end{array}$ \\
\hline Bearing R 2 & 9 & 11 \\
\hline Bearing 625 & 12 & 14 \\
\hline Bearing 626 & 12 & 14 \\
\hline Bearing 608 & 12 & 14 \\
\hline Roller & 12 & 14 \\
\hline
\end{tabular}

\subsubsection{Preventive Maintenance Cost}

Cost incurred by the company, including:

1. Component Purchase Cost

The purchase price component of filling machine that failure can be seen in Table 2 .
Table 2. Component Price

\begin{tabular}{|l|c|c|}
\hline Component & $\begin{array}{c}\text { Component } \\
\text { Number } \\
\text { (Unit/replace) }\end{array}$ & $\begin{array}{c}\text { Component } \\
\text { Price (Rp) }\end{array}$ \\
\hline Bearing R 2 & 12 & 15.000 \\
\hline Bearing 625 & 12 & 30.000 \\
\hline Bearing 626 & 12 & 30.000 \\
\hline Bearing 608 & 4 & 25.000 \\
\hline Roller & 6 & 20.000 \\
\hline
\end{tabular}

2. Maintenance Technician Cost

Preventive and corrective maintenance is done by a permanent technician. Technicians perform maintenance for 8 hours work/day, if maintenance is done beyond working hours it will be done overtime. The overtime fee is $\mathrm{Rp} \mathrm{15.000/hour.}$

3. Unemployed Operators Cost

The cost of idle operators is the cost incurred when the machine is undergoing preventive or corrective maintenance, while the operator is still paid every month. There are six operators. The operator fee is $\mathrm{Rp}$ 15.000/hour.

4. Lost Profits

If the machine is broken suddenly, the production process will be halt. It causes the production target not will be reached and the company will lose their profit. The profit lost is Rp 423.998/hour.

5. Downtime and Failure Frequency

Downtime of the machine is required to know how long the machine will breakdown. Downtime occurs due to expected technician waiting time and failure time. Expected technician waiting time is 5,67 hours. This downtime will influence the idle operator and the lost profits on the failure impact cost.

Failure frequency is the number of failures that occurred over a span of three years from 2014 to 2016. Downtime dan failure frequency can be seen on Table 3 .

Table 3. Downtime dan Failure Frequency

\begin{tabular}{|l|c|c|}
\hline Component & $\begin{array}{c}\text { Average } \\
\text { Downtime } \\
\text { (hour) }\end{array}$ & $\begin{array}{c}\text { Failure } \\
\text { Frequency }\end{array}$ \\
\hline Bearing R 2 & 17,67 & 7 \\
\hline Bearing 625 & 19,67 & 4 \\
\hline Bearing 626 & 19,67 & 3 \\
\hline Bearing 608 & 19,67 & 3 \\
\hline Roller & 19,67 & 2 \\
\hline
\end{tabular}

\subsection{Data Processing}

Data processing contains the determination of critical components, determination of failure distribution, parameter determination and calculation of component preventive maintenance interval. 


\subsubsection{Determination of Critical Component}

Critical components are selected based on the highest maintenance cost and affect to the other components if it's get failure, which can cause the company loses their profit. The calculation of the selection of critical components in the filling machine can be seen in Table 4.

Table 4. Calculation of Filling Machine Critical Component

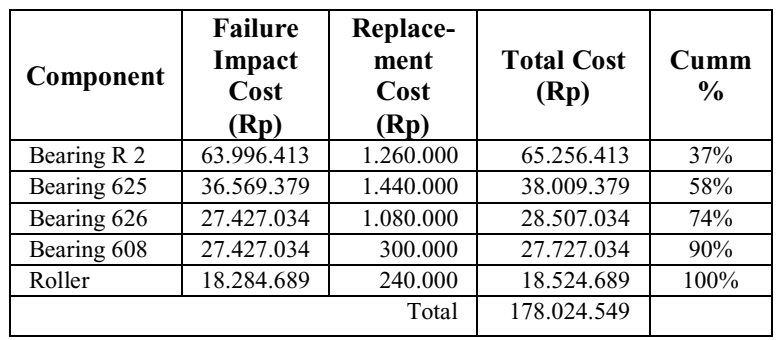

Example Calculation of Component Bearing R 2:

- Component Purchase Cost

$=$ Number of components $\times$ Component Price

$=12$ unit $\mathrm{x} \operatorname{Rp} 15.000$

$=\mathrm{Rp} 180.000 /$ unit bearing $\mathrm{R} 2$

- Replacement Cost $=$ Purchase Cost $\mathrm{x}$ Frequency of Failure

$=\mathrm{Rp} 180.000 \times 7$

$=\mathrm{Rp} 1.260 .000$

- Failure Impact Cost $=($ Unemployed Operator Cost + Maintenance Technician Cost + Lost Profit) $\mathrm{x}$ frequency of failure

$=(6$ people $\times \mathrm{Rp} 15.000 \times 17,67$ hours $)+(4$ hours $\mathrm{x}$ Rp15.000) + (Rp $423.998 \times 17,67$ hours $) \times 7$

$=\operatorname{Rp} 63.996 .413$

- Total Bearing Cost R 2 = Replacement Cost + Failure Impact Cost

$=\operatorname{Rp} 1.260 .000+\operatorname{Rp} 63.996 .413$

$=\operatorname{Rp} 65.256 .413$

- Percentage $=($ Total Component Bearing Cost R2/Total Cost) $\mathrm{x} 100 \%$

$=\operatorname{Rp} 65.256 .413 / \operatorname{Rp} 178.024 .549=37 \%$

The critical components selected are the most influential components of bearing R2, bearing 625 and bearing 626 . Components bearings 608 and roller are not selected because the cost percentage is not more than $20 \%$ and the total cost does not have a big effect.

\subsubsection{Determination of Failure Distribution}

The component corrective interval is obtained from the day moments of failure performance and the machine can be used until the component is failure again. Below, for example time interval of failure component bearing R2 can be seen in Table 5 .
Table 5. Interval of Failure Bearing R2

\begin{tabular}{|c|l|c|}
\hline No & Date of Failure & $\begin{array}{c}\text { Failure Interval } \\
\text { (days) }\end{array}$ \\
\hline 1 & $04-F e b-14$ & \\
\hline 2 & $21-J u l-14$ & 167 \\
\hline 3 & $10-$ Nov-14 & 112 \\
\hline 4 & $16-$ Mar-15 & 126 \\
\hline 5 & 10 -Nov-15 & 239 \\
\hline 6 & 03 -Feb-16 & 85 \\
\hline 7 & 23 -Agu-16 & 202 \\
\hline
\end{tabular}

The selected distribution pattern is the largest index of fit value, the recapitulation of selected failure distribution pattern can be seen in Table 6 .

Table 6. Recapitulation of Failure Distribution Pattern

\begin{tabular}{|c|l|c|}
\hline No & Components & $\begin{array}{c}\text { Selected Failure } \\
\text { Distribution Pattern }\end{array}$ \\
\hline 1 & Bearing R 2 & Lognormal \\
\hline 2 & Bearing 625 & Weibull \\
\hline 3 & Bearing 626 & Lognormal \\
\hline
\end{tabular}

\subsubsection{Parameter Failure Distribution Determination}

The calculation of distribution parameters based on the selected failure distribution for each component. Example for bearing R2 can be seen on Table 7.

Table 7. Lognormal Distribution Parameters

\begin{tabular}{|c|c|c|c|c|c|}
\hline No(i) & $\mathbf{T}_{\mathbf{i}}$ & $\mathbf{X}_{\mathbf{i}}$ & M & $(\mathbf{X} \mathbf{i}-\mu)^{2}$ & $\sigma$ \\
\hline 1 & 85 & 4,443 & \multirow{6}{*}{4,984} & 0,292 & \multirow{6}{*}{0,354} \\
\hline 2 & 112 & 4,718 & & 0,070 & \\
\hline 3 & 126 & 4,836 & & 0,022 & \\
\hline 4 & 167 & 5,118 & & 0,018 & \\
\hline 5 & 202 & 5,308 & & 0,106 & \\
\hline 6 & 239 & 5,476 & & 0,243 & \\
\hline Total & 931 & 29,900 & & 0,751 & \\
\hline
\end{tabular}

Calculation Example:

$$
\begin{aligned}
X i & =\ln t i=\ln 85=4,442651 \\
\mu= & \overline{X \imath}=\frac{\sum_{i=1}^{n} \ln \mathrm{ti}}{n} \\
= & \frac{29,9001}{4} \\
& =4,984 \\
\sigma & =\sqrt{\frac{\sum_{i=1}^{n}(X i-\mu)^{2}}{n}} \\
& =\sqrt{\frac{0,75099}{6}} \\
& =0,354
\end{aligned}
$$

$$
\begin{aligned}
\text { MTTF } & =\exp \left(\mu+\frac{\sigma^{2}}{2}\right) \\
& =\exp \left(29,90016+\frac{0,3537^{2}}{2}\right) \\
& =165,43 \text { days }
\end{aligned}
$$

\subsubsection{Calculation of Component Preventive Maintenance Interval}

Before calculation of preventive maintenance interval using equation (1), recapitulation of preventive and 
corrective maintenance costs of bearing R2, bearing 625 , and bearing 626 can be seen on Table 8 .

Table 8. Preventive and Corrective Maintenance Cost

\begin{tabular}{|l|c|r|}
\hline Component & $\begin{array}{c}\text { Preventive Cost } \\
\text { (Rp) }\end{array}$ & $\begin{array}{c}\text { Corrective Cost } \\
\text { (Rp) }\end{array}$ \\
\hline Bearing R 2 & 1.095 .000 & 9.322 .338 \\
\hline Bearing 625 & 1.395 .000 & 10.560 .334 \\
\hline Bearing 626 & 1.395 .000 & 10.560 .334 \\
\hline
\end{tabular}

Calculation of component replacement intervals based on calculation of distribution functions selected at a particular time unit and the determination of optimal component replacement intervals selected based on the expectation of total replacement cost per unit time (C (tp)) the smallest [3].

Interval calculation component Bearing R2 based on lognormal distribution, 60 days is the optimum point because it has the smallest value of $\mathrm{C}(\mathrm{tp})$ which is worth Rp 5.059/day can be seen on Table 9.

Table 9. Preventive Maintenance Interval Bearing R2

\begin{tabular}{|c|c|c|c|c|}
\hline $\begin{array}{c}\text { tp } \\
\text { (day) }\end{array}$ & $F_{(} t p_{)}$ & $R_{c} t p_{j}$ & $\begin{array}{c}(t p+T p) \cdot R_{C} t p_{3}+ \\
\left(M_{C} t p_{)}+T f\right) \cdot\left(1-R_{C} t p_{3}\right)\end{array}$ & $\begin{array}{c}\mathbf{C}_{\mathrm{C}} \text { tp) } \\
\text { (Rp/day) }\end{array}$ \\
\hline 10 & 0,0000 & 1,0000 & 176,545 & 6.202 \\
\hline 20 & 0,0000 & 1,0000 & 186,545 & 5.870 \\
\hline 30 & 0,0000 & 1,0000 & 196,545 & 5.571 \\
\hline 40 & 0,0001 & 0,9999 & 206,540 & 5.307 \\
\hline 50 & 0,0012 & 0,9988 & 216,484 & 5.105 \\
\hline 60 & 0,0060 & 0,9940 & 226,189 & 5.059 \\
\hline 70 & 0,0189 & 0,9811 & 235,231 & 5.315 \\
\hline 80 & 0,0446 & 0,9554 & 242,997 & 6.015 \\
\hline 90 & 0,0858 & 0,9142 & 248,856 & 7.237 \\
\hline 100 & 0,1425 & 0,8575 & 252,350 & 8.984 \\
\hline
\end{tabular}

The calculation of component Bearing 625 the interval based on the weilbull distribution, 80 days is the optimal point because it has the smallest value of $C(t p)$ which is worth Rp 29.118/day. The calculation of component preventive maintenance intervals can be seen in Table 10 .

Table 10. Preventive Maintenance Interval Bearing 625

\begin{tabular}{|c|c|c|c|c|}
\hline $\begin{array}{c}\text { tp } \\
\text { (day) }\end{array}$ & $F_{(t} t p_{)}$ & $R_{(} t p_{)}$ & $\begin{array}{c}(t p+T p) \cdot R_{(} t p_{)}+ \\
\left(M_{t} t p_{)}+T f\right) \cdot\left(1-R_{C} t p_{)}\right)\end{array}$ & $\begin{array}{c}\mathrm{C}_{\mathrm{C}} \mathrm{tp}_{\mathrm{J}} \\
\text { (Rp/day) }\end{array}$ \\
\hline 40 & 0,0010 & 0,9820 & 40,658 & 38.389 \\
\hline 50 & 0,0013 & 0,9701 & 49,891 & 33.456 \\
\hline 60 & 0,0017 & 0,9550 & 58,693 & 30.791 \\
\hline 70 & 0,0020 & 0,9367 & 66,967 & 29.495 \\
\hline 80 & 0,0023 & 0,9151 & 74,619 & 29.118 \\
\hline 90 & 0,0026 & 0,8905 & 81,560 & 29.411 \\
\hline 100 & 0,0029 & 0,8629 & 87,714 & 30.232 \\
\hline 110 & 0,0032 & 0,8325 & 93,017 & 31.499 \\
\hline 120 & 0,0034 & 0,7997 & 97,417 & 33.164 \\
\hline 130 & 0,0036 & 0,7647 & 100,878 & 35.206 \\
\hline 140 & 0,0038 & 0,7279 & 103,381 & 37.620 \\
\hline 150 & 0,0039 & 0,6895 & 104,923 & 40.416 \\
\hline
\end{tabular}

The calculation of component Bearing 626 the interval based on the lognormal distribution, 40 days is the optimal point because it has the smallest value of $C(t p)$ which is worth $\mathrm{Rp}$ 6.564/day. The calculation of component preventive maintenance intervals can be seen in Table 11 .
Table 11. Preventive Maintenance Interval Bearing 626

\begin{tabular}{|c|c|c|c|r|}
\hline $\begin{array}{c}\text { tp } \\
\text { (day) }\end{array}$ & F(tp) & $\mathbf{R}_{(\mathbf{t p})}$ & $\begin{array}{c}\text { (tp+Tp).R(tp) }+ \\
(\mathbf{M} \text { (tp)+Tf).(1- } \\
\text { R(tp) }\end{array}$ & $\begin{array}{c}\text { C(tp) } \\
\text { (Rp/day) }\end{array}$ \\
\hline 10 & 0,0000 & 1,0000 & 193,325 & 7.216 \\
\hline 20 & 0,0002 & 0,9998 & 203,321 & 6.870 \\
\hline 30 & 0,0019 & 0,9981 & 213,268 & 6.623 \\
\hline $\mathbf{4 0}$ & $\mathbf{0 , 0 0 7 5}$ & $\mathbf{0 , 9 9 2 5}$ & $\mathbf{2 2 3 , 0 2 7}$ & $\mathbf{6 . 5 6 4}$ \\
\hline 50 & 0,0191 & 0,9809 & 232,379 & 6.755 \\
\hline 60 & 0,0374 & 0,9626 & 241,093 & 7.209 \\
\hline 70 & 0,0625 & 0,9375 & 248,973 & 7.904 \\
\hline 80 & 0,0934 & 0,9066 & 255,886 & 8.798 \\
\hline 90 & 0,1290 & 0,8710 & 261,762 & 9.847 \\
\hline 100 & 0,1680 & 0,8320 & 266,588 & 11.009 \\
\hline 110 & 0,2092 & 0,7908 & 270,394 & 12.250 \\
\hline
\end{tabular}

\section{Analysis}

PT Lucas Djaja has 6 machines used during injection production process. The six machines include distillation machines, washing machines, oven machines, mixing machines, filling machines, and autoclave machines. The criteria for this critical machine selection diagram pareto is seen from the frequency of error occurring in the past. According to pareto chart, the most frequently error happened in filling machine, the cause of this filling machine error due to bearing composing components.

These criteria are seen from the amount of component maintenance cost and the consequent of letting the component failure. Components selection are selected by showing the biggest cost incurred by the company if the component is error. The error components can cause hampering of production process and the lost of company's profit. The critical components selected on filling machine are bearing R2, bearing 625 and bearing 626.

Determination of time interval for critical components maintenance is done by using age replacement method with minimization total maintenance cost. For the determination of preventive maintenance interval is determined by calculating $C(t p)$ which is repeatedly calculated to obtain the smallest $\mathrm{C}(\mathrm{tp})$. The method used to determine the optimal preventive maintenance interval of filling machine for component bearing R2, bearing 625 , and bearing 626 is age replacement method developed by Jardine (1973). The purpose of this method is to know the optimal preventive maintenance interval with minimal maintenance cost. So, the interval with the smallest $C(t p)$ is the optimal component maintenance time. This method is suitable to use in research to remember the lifetime of the components affected by its usage.

\section{Conclusions}

Based on the finding and discussion of the data above, it can be concluded as below:

1. On the corrective maintenance schedule done by the company, calculated using the formula of mean time to failure, it obtained the result of maintenance of filling machine component bearing $\mathrm{R} 2$ at 165 days, bearing 625 at 205 days, bearing 626 at 182 days. 
2. On the calculation result using age replacement method, the calculation interval of preventive maintenance for filling machine component bearing $\mathrm{R} 2$ at point 60 days. bearing 625 at 80 days. bearing 626 at point 40 days.

3. On the result of the failures cost, and if the cost is done only the preventive maintenance has the difference on bearing R2 Rp 8.227.338, bearing 625 Rp 9.165.334, and bearing $626 \mathrm{Rp}$ 9.165.334. The cost has a big difference because at the cost of corrective maintenance there are advantages lost and the downtime is too long.

\section{References}

1. A. Corder, S,. Teknik Manajemen Pemeliharaan, (Erlangga, Jakata, 1988)

2. C. Ebeling, An Introduction to Reliability and Maintainability Engineering (McGraw-Hill Companies, Singapore, 1997)

3. A. Jardine, K.S., Maintenance, Replacement, and Reliability (Pitman Publishing Corporation, Canada, 1973)

4. J. Usher, S., Kamal, A.H., Syed, W.H., IIE Transactions, 30, 1121-1128 (1998)

5. O’Connor, P.D.T., Practical Reliability Engineering (John Willey \& Sons, New York, 1991)

6. R. Walpole, E. \& Myers, R.H. Probability and Statistics for Engineers and Scientists, (Macmillan Publishing Co, New York, 5th ed., 1993)

7. S. Wignjosoebroto, Pengantar Teknik \& Manajemen Industri (Guna Widya, 2006) 